\title{
Development and evaluation of an integrated emergency response facility location model
}

\author{
Jae-Dong Hong ${ }^{1}$, Yuanchang Xie ${ }^{2}, \mathrm{Ki}_{\text {-Young Jeong }}{ }^{3}$ \\ ${ }^{1}$ South Carolina State University, ${ }^{2}$ University of Massachusetts Lowell, ${ }^{3}$ University of Houston-Clear \\ Lake (UNITED STATES) \\ jhong@scsu.edu,yuanchang_xie@uml.edu,jeongk@ubcl.edu
}

Received October 2011

Accepted February 2012

\section{Abstract:}

Purpose: The purpose of this paper is to propose and compare the performance of the "two" robust mathematical models, the Robust Integer Facility Location (RIFL) and the Robust Continuous Facility Location (RCFL) models, to solve the emergency response facility and transportation problems in terms of the total logistics cost and robustness.

Design/methodology/approach: The emergency response facilities include distribution warehouses (DWH) where relief goods are stored, commodity distribution points (CDP), and neighborhood locations. Authors propose two robust models: the Robust Integer Facility Location (RIFL) model where the demand of a CDP is covered by a main DWH or a backup CDP; the Robust Continuous Facility Location (RCFL) model where that of a CDP is covered by multiple DWHs. The performance of these models is compared with each other and to the Regular Facility Location (RFL) model where a CDP is covered by one main DWH. The case studies with multiple scenarios are analyzed.

Findings: The results illustrate that the RFL outperforms others under normal conditions while the RCFL outperforms others under the emergency conditions. Overall, the total logistics cost and robustness level of the RCFL outperforms 
those of other models while the performance of RFL and RIFL is mixed between the cost and robustness index.

Originality/value: Two new emergency distribution approaches are modeled, and evaluated using case studies. In addition to the total logistics cost, the robustness index is uniquely presented and applied. The proposed models and robustness concept are hoped to shed light to the future works in the field of disaster logistics management.

Keywords: emergency response, facility location, disaster recovery, emergency relief goods, spreadsheet model, facility disruptions

\section{Introduction}

After emergency events such as natural disasters or terrorist attacks, it is critical through emergency response facilities to distribute for rapid recovery emergency supplies to the affected areas in a timely and efficient manner. The emergency response facilities considered in this paper include distribution warehouses ( $D W H s$ ), where emergency relief goods are stored, intermediate response facilities termed Disaster Recovery Centers ( $D R C s$ ), sometimes referred to as break of bulk points $(B O B s)$, where emergency relief goods can be sent to the affected area in a timely manner for rapid recovery, and neighborhood locations in need of relief goods. The distribution of emergency supplies from these facilities to the affected areas must be done via a transportation network. Given the significance of transportation costs and the time involved in transporting the relief goods, the importance of optimally locating DWHs and BOBs in the transportation network is apparent.

Traditional facility location models, such as set-covering models, p-center models, p-median models, and fixed charge facility location problems (Dekle, Lavieri, Martin, Emir-Farinas \& Francis, 2005) implicitly assume that emergency response facilities will always be in service or be available, and each demand node is assumed to be satisfied by a supply facility as assigned by the optimization model. However, it is very likely that some emergency response facilities may be damaged or completed destroyed and cannot provide the expected services. When this happens, the demands of the affected areas will have to be satisfied by other facilities much farther away than the initially assigned facilities. This obviously will increase the distribution cost and time of relief goods. Compared to the prior- 
disaster transportation costs minimized by the traditional facility location models, the actual or post-disaster transportation costs can be substantially higher. Thus, it is very important to take into account the post-disaster costs as well as the priordisaster costs in emergency response facility location modeling.

In light of the significant difference in siting between emergency response facilities and other types of facilities and the paucity of the research literature in this area, we propose a new emergency response facility location model that can better account for the uncertainty caused by the disruptions of critical infrastructure and that would minimize the post-disaster costs. Assuming that some DWHs might be unavailable after disastrous events, we compare the new model with a traditional facility location model based on case studies to demonstrate the developed model's capability to better deal with the risks in emergency response caused by the disruptions of critical infrastructure.

\section{Literature review}

Facility location models have been extensively researched for decades. Dekle et al. (2005) develop a set-covering model and a two-stage modeling approach to identify the optimal $D R C$ sites. Their objective is to minimize the total number of $D R C s$, subject to each county's residents being within a certain distance of the nearest $D R C$. Horner and Downs (2007) conduct a similar study to optimize $B O B$ locations (in our paper, $B O B S$ and $D R C s$ are used interchangeably). As shown in Figure 1, emergency relief goods are shipped from central distribution warehouses to $B O B$ s and distributed to victims of catastrophes. Given the number and locations of initial warehouses, Horner and Downs formulate the problem as a multi-objective integer programming. Two objectives are considered. The first objective is to minimize the transportation costs of servicing $B O B s$ from warehouse locations, and the second one is to minimize the transportation costs between $B O B S$ and neighborhoods in need of relief goods.

Snyder and Daskin (2005) develop a reliable facility location model based on the pmedian and the incapacitated fixed-charge location problem. They defined the extra transportation cost caused by the failure of one or more facilities as the "failure cost". Obviously, adding additional facilities as backups would reduce the failure cost. However, this will increase the day-to-day system operating cost. The main goal of their model is to find the best "trade-off" between the operating cost and the expected failure cost of a facility location design. The developed model is solved by a Lagrangian relaxation algorithm. Berman, Krass and Menezes (2007) also 
develop a reliable facility location model based on the p-median problem. In their research, each facility is assigned a failure probability. The objective is to minimize the expected weighted transportation cost and the expected penalty for certain customers not being served. The developed model has a nonlinear objective function and is difficult to solve by exact algorithms. These authors thus proposed a greedy heuristic for their model.

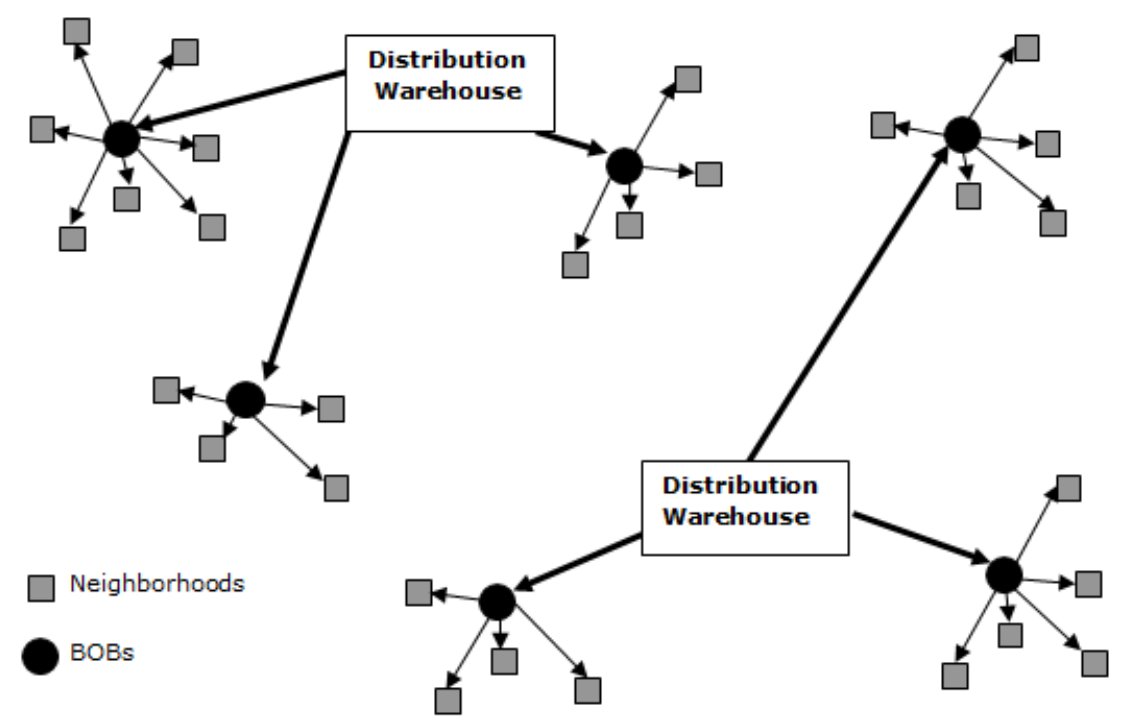

Figure 1. Distribution strategy for emergency relief goods (Horner \& Downs, 2007)

Hassin, Ravi and Salman (2010) investigate a facility location problem considering the failures of network edges. Their goal is to maximize the expected demand that can be served after disastrous events. In their study, it is assumed that a demand node can be served by a facility if it is within a certain distance of the entity in the network that survived disaster. The failures of network edges are assumed to be dependent on each other. These authors formulate the problem as an exact dynamic programming model and develop an exact greedy algorithm to solve it. Eiselt, Gendreau and Laporte (1996) also propose a reliable model for optimally locating $p$ facilities in a network that takes into account the potential failures of road network links and nodes. These authors develop a low-order polynomial algorithm to solve the proposed facility location model.

Li and Ouyang (2010) examined a continuous reliable incapacitated fixed charge location (RUFL) problem. They assume that facilities are subject to spatially correlated disruptions and have a location-dependent probability to fail during disastrous events. A continuum approximation (Langevin, Mbaraga \& Campbell, 1996; Daganzo, 2005) approach is adopted to solve the developed model. The 
authors consider two methods to model the spatial correlation of disruptions, including positively correlated Beta-Binomial facility failure.

Cui, Ouyang \& Shen (2010) investigate a discrete reliable facility location design problem under the risk of disruptions. Their model considers a set of $i$ customers and $j$ facilities, with the goal of minimizing the sum of fixed facility and expected transportation costs. Similar to Snyder and Daskin (2005), Cui et al. (2010) assign each customer to multiple levels to ensure the robustness of the final facility location design. They also develop a Lagrangian relaxation algorithm to solve the proposed model.

Our research is built upon the work done by Horner and Downs (2007) and also motivated by the recent trend in facility location studies to consider the risk caused by critical infrastructure disruptions. Contrary to the one-stage model developed by Horner and Downs and which optimized the location of BOBs only, we develop a two-stage integrated facility location model that simultaneously optimizes the locations of $D W H s$ and BOBs. In addition, we propose two robust models for the case of disasters.

The rest of this paper is organized as follows. In the next section, an integrated facility location model is introduced. Based on this integrated model formulation, robust integrated facility location models are proposed and described in detail. Following the description of the model formulations, case studies are conducted and the resulting analysis is presented. The last section summarizes the developed models and research findings. It also provides recommendations for future research directions.

\section{Development of integrated facility location model}

Let $M$ be the set of all neighborhoods and potential distribution warehouse locations, indexed by $m$. We separate $M$ into two sets: $M=\{N, I\}$, where $I$ denotes the set of potential distribution warehouse locations (indexed by $i=1,2, \ldots, w$ ) and $N$ represents the set of neighborhoods (indexed by $n=1,2, \ldots, p$ ). In this research, we assume BOBs can be located at any neighborhoods and potential DWH locations, while DWH can be built at candidate DWH locations only. Based on these two assumptions, let $J$ be the set of potential BOB locations indexed by $j \in\{M\}$, where $j=1,2, \ldots p, p+1, p+2, \ldots p+i, \ldots, p+w$. Given this problem setting, we formulate the following integer quadratic programming (IQP) model that minimizes the total logistics cost, which is the sum of fixed facility costs and the transportation 
costs from $D W H s$ to $B O B s$ and between $B O B s$ and neighborhoods/candidate $D W H$ locations that are not selected:

$$
\begin{aligned}
\text { Minimize } Z & =\left[\sum_{i \in I} a_{i} W_{i}+\sum_{i \in I} \sum_{j \in M}\left(\sum_{m \in M} D_{m} y_{j m}\right) d_{i j} x_{i j}\right] \\
& +\left[\sum_{j \in M} b_{j} B_{j}+\sum_{j \in M} \sum_{m \in M} D_{m} d_{j m} y_{j m}\right]
\end{aligned}
$$

Subject to

$$
\begin{gathered}
\sum_{i \in I} W_{i} \leq D_{W}, \\
W_{i}+B_{p+i} \leq 1, \quad \forall i \in I \\
W_{i}+\sum_{j \in M} y_{j(p+i)}=1, \quad \forall i \in I \\
\sum_{j \in M} y_{j n}=1, \quad \forall n \in N \\
k_{i} \cdot W_{i} \leq \sum_{j \in M} x_{i j} \leq K_{i} \cdot W_{i}, \quad \forall i \in I \\
\sum_{i \in I} x_{i j}=B_{j}, \quad \forall j \in M \\
\sum_{j \in M} B_{j} \leq D_{B}, \quad \forall j \in M \\
B_{j} \cdot L_{j} \leq \sum_{m \in M} y_{j m} \leq B_{j} \cdot U_{j}, \\
\forall j \text { and } \forall m \in M
\end{gathered}
$$

where,

$a_{i}$ : fixed cost for contructing and operating $D W H_{i} ;$

$\mathrm{b}_{\mathrm{j}}$ : fixed cost for contructing and operating $B O B_{j}$; 
$\mathrm{B}_{\mathrm{j}}: 1$ if neighborhood $j$ is selected as a $\mathrm{BOB}, 0$ otherwise (decision variable);

$\mathrm{d}_{\mathrm{ij}}$ : distance between $D W H_{i}$ and $B O B_{j} ;$

$\mathrm{d}_{\mathrm{im}}$ : distance between $D W H_{i}$ amd location $m$;

$\mathrm{d}_{\mathrm{jm}}$ : distance between $B O B_{j}$ and location $m$;

$D_{B}$ : maximum number of $B O B s$ can be built (set to 5 );

$D_{m}$ : demand of location (can be either neighborhood or $D W H$ ) $m$;

$\mathrm{D}_{\mathrm{w}}$ : maximum number of $D W H s$ can be built (set to 3 in this study);

$\mathrm{k}_{\mathrm{i}}$ : maximum number of $B O B s$ a $D W H$ must handle (set to 1 in this study);

$\mathrm{K}_{\mathrm{i}}$ : maximum number of $B O B s$ a $D W H$ can handle (set to 5 in this study);

$\mathrm{L}_{\mathrm{j}}$ : minimum number of neighborhoods a $B O B$ needs to cover (set to 2);

$\mathrm{U}_{\mathrm{j}}$ : maximum number of neighborhoods a $B O B$ can cover (set to 6 );

$\mathrm{W}_{\mathrm{i}}: 1$ if a candidate warehouse $i$ is selected, 0 otherwise (decision variable);

$\mathrm{x}_{\mathrm{ij}}: 1$ if $B O B_{j}$ is covered by $D W H_{i}, 0$ otherwise (decision variable);

$\mathrm{y}_{j \mathrm{~m}}: 1$ if location $m$ is covered by $C D P_{j,} 0$ otherwise (decision variable).

Since the main purpose of this paper is to demonstrate how the proposed model works, we further simplify the objective function by excluding the fixed cost terms for $B O B s$ and for $D W H$. Also, the numbers of $B O B s$ and $D W H s$ to be built are prespecified. For real-world applications, once the real data are available, such restrictions can be readily relaxed to generate meaningful results. In this paper, we use the following simplified objective function for the simultaneous optimization of $D W H$ and $B O B$ locations.

$$
\text { Minimize } Z=\left[\sum_{i \in I} \sum_{j \in M}\left(\sum_{m \in M} D_{m} y_{j m}\right) d_{i j} x_{i j}\right]+\left[\sum_{j \in M} \sum_{m \in M} D_{m} d_{j m} y_{j m}\right]
$$

Constraints (2) require that at most $D_{W} D W H s$ can be constructed; $D_{W}$ is provided by the user. 
Constraints (3) ensure that the potential DWH location will not be selected simultaneously as both $D W H$ and $B O B$.

Constraints (4) ensure that if a potential $D W H$ location $i$ is not selected (i.e., $W_{i}=0$ ) (its demand must be satisfied by a $B O B$ ).

Constraints (5) make certain that each neighborhood $(n \in N)$ is assigned to exactly one $B O B$.

Constraints (6) limit the minimum and maximum number of $B O B s$ to be served by each $D W H$.

Constraint (7) ensure that DWHs only supply the selected BOBs, not all candidate BOBs.

Constraints (8) limit the total number of selected $B O B s$ to be less than or equal to a user-specified number, $D_{B}$.

Constraints (9) ensure that neighborhoods or unselected $D W H$ locations can only be assigned to the candidate $B O B s$ that are finally selected.

Constraints (10) ensure that each selected candidate $B O B$ must cover a minimum number of $L_{j}$ neighborhoods and can only cover a maximum of $U_{j}$ neighborhoods. Hereafter, this newly introduced model given by Equations (2)-(11) is referred to as the Integrated Facility Location (IFL) model.

\section{Development of robust optimization models}

A property of the IFL model is that the optimal plan generated by it may not be optimal after disastrous events. If a $D W H$ becomes unavailable after the disaster, $B O B s$ assigned to this $D W H$ need to be reassigned to other adjacent $D W H s$ with extra capacity. Then the post-disaster logistics cost may become much larger than the pre-disaster optimal cost. To reduce post-disaster logistics cost, one potential solution is to require each $B O B$ to be covered by a backup $D W H$ as well as a main $D W H$. To do that, we solve the IFL model after changing the right-hand-side of Equation (4) to be 2 from 1 and find the optimal $D W H$ and $B O B$ locations, denoted by $W_{i}{ }^{* 2}$ and $B_{j}{ }^{* 2}$. We call this model the Robust Integer Facility Location (RIFL) model. Note that the robust model would minimize the post-disaster cost, not the pre-disaster cost. To find the pre-disaster cost for the RIFL model, we solve for the optimal coverage of BOBS and neighbors, $x_{i j}{ }^{*}$ and $y_{j m}{ }^{*}$, after setting the RHS of Equation (4) back to be 1 , with the $W_{i}^{* 2}$ and $B_{j}^{* 2}$ fixed. 
An alternative way of developing the robust model is to add the capacity constraints of candidate $D W H s$ in a disaster-prone area. For instance, if a $D W H$ has a high probability of being damaged in disastrous events, one can specify that all BOBS assigned to this $D W H$ can only have up to certain percentages of their demand satisfied by it. This strategy would avoid putting all eggs in one basket and improve the robustness of the model. In fact, if a $D W H$ is partially damaged due to disaster, this model would be useful. Now, let $x_{i j}$ be a continuous decision variable between 0 and 1 , denoting the fraction of $B O B_{j}{ }^{\prime}$ s demand satisfied by $D W H_{i}$. Then, the following capacity constraint is added to the IFL model:

$$
0 \leq x_{i j} \leq C_{i} \cdot B_{j}, \quad \forall i \in I \text { and } \forall j \in M
$$

Where, $C_{i}$ : maximum fraction of $B O B^{\prime}$ s demand that can be satisfied by $D W H_{i}$

For candidate $D W H s$ with a high probability of damage or shutdown during disastrous events, $C_{i}$ would take relatively smaller values, whereas for DWHs in stable and safe areas, $C_{i}$ would take larger values. By making $x_{i j}$ a continuous decision variable, the robust facility location model becomes a mixed integer quadratic programming (MIQP) problem, which can be linearized by defining a new decision variable as follows:

$$
z_{i j m}=x_{i j} \cdot y_{j m}
$$

Where $z_{i j m}$ denotes the fraction of neighborhood $m$ 's demand satisfied by $D W H_{i}$ via $B O B_{j}$. Then solving this robust facility location problem is equivalent to solving the following mixed integer linear programming (MILP) problem:

$$
\text { Minimize } Z=\left[\sum_{i \in I} \sum_{j \in M} \sum_{m \in M} D_{m} d_{i j} z_{i j m}\right]+\left[\sum_{j \in M} \sum_{m \in M} D_{m} d_{j m} y_{j m}\right]
$$

Subject to equations $2,3,4,5,7,8,9$ and 10;

$$
\begin{gathered}
C_{i} k_{i} W_{i} \leq \sum_{j \in M} x_{i j} \leq C_{i} K_{i} W_{i}, \quad \forall i \in I \\
0 \leq x_{i j} \leq C_{i} \cdot B_{j}, \quad \forall i \in I \text { and } \forall j \in M \\
\operatorname{Max}\left\{0, x_{i j}+y_{j m}-1\right\} \leq z_{i j m} \leq \frac{x_{i j}+y_{j m}}{2}, \quad \forall i \in I \text { and } \forall j, \forall m \in M
\end{gathered}
$$




$$
0 \leq C_{i} \leq 1, \quad \forall i \in I
$$

We call the above model the Robust Continuous Facility Location (RCFL) model. Note that if $C_{i}=1, \forall \mathrm{i}$, the RCFL model is equivalent to the IFL model and produces exactly the same solutions. To find the pre-disaster cost for the RCFL model, we solve the RCFL model by adjusting $C_{i}$, such that the post-disaster cost is minimized. Then with $W_{i}^{*}$ and $B_{j}^{*}$ obtained for the minimum post-disaster cost fixed and $C_{i}=1$, $\forall \mathrm{i}$, we solve the RCFL model again and the resulting total cost will be the predisaster cost.

\section{$5 \quad$ Case study and observations}

The integrated model and two robust models can be solved by a variety of optimization software packages, such as LINDO, LINGO, or GAMS. However, coding the developed MILP model using these tools may not be an easy task, since so many decision variables and constraints are involved. Recently, many researchers and practitioners are paying significant attention to Microsoft Excel spreadsheet-based optimization modeling because of its non-algebraic approach. Several powerful software packages based on the Excel spreadsheet model, such as Solver, What's Best, CPLEX, etc., make Excel spreadsheet-based modeling attractive. In this paper, a CPLEX for Microsoft Excel Add-In is used to solve the proposed MILP model.

To evaluate the developed MILP model, we conduct a case study using cities in South Carolina. 20 cities are selected as neighborhoods and 5 cities among neighborhoods, with Charleston, Columbia, Florence, Greenville, and Orangeburg considered as candidate sites for DWHs, as shown in Figure 2. All neighborhoods are candidate locations for BOBs. Tables $1(\mathrm{a}), 1(\mathrm{~b})$ and 1 (c) show the distances (in miles) between any two neighborhoods. Also shown in Table 1(c) are the demands (in thousands) for all neighborhoods. These demands are hypothetical values proportional to each neighborhood's year 2000 population and can be readily replaced by true demand data for real-world applications. Based on these input data, an Excel Spreadsheet model is developed. 


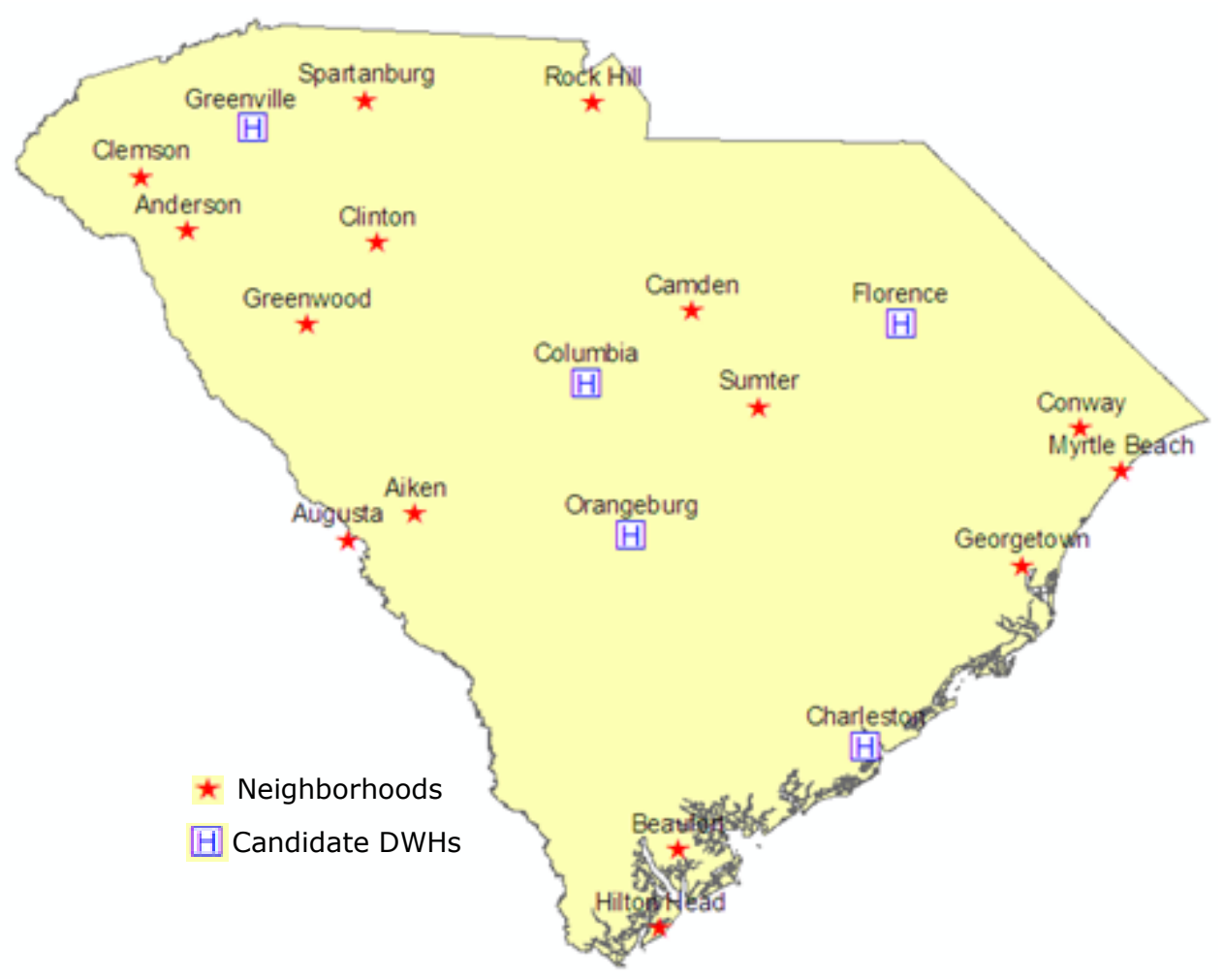

Figure 2. Candidate Warehouses, BOBs, and Neighborhoods

We solve the three models, IFL, RIFL, and RCFL. To show how robust the RIFL and RCFL models are, two scenarios are considered. The first (normal) scenario assumes that all candidate $D W H$ s remain available after disastrous events, whereas the second considers the shutdown/unavailability of a $D W H$. Hereafter, these scenarios are referred to as normal and shutdown scenarios, respectively. For normal scenario, we evaluate and present the results of facility location and transportation scheme as shown in Tables 2(a), 2(b) and 2(c). From the results under normal scenario in Tables 2(a), 2(b) and 2(c), we see that all three models include Columbia and Charleston as DWHs. Thus, it would be interesting to see what would happen if one of DWHs is unavailable and to compare the post-disaster costs of the three models. We select DWH Columbia to be unavailable after disaster, evaluate the three models, and present the results in Tables 2(a), 2(b) and $2(\mathrm{c})$, under the shutdown scenario.

Note that in Tables 2(a), 2(b) and 2(c), we assume that Columbia, the unavailable $D W H$ for the shutdown case, can still cover the Columbia area and consequently is not assigned to any $B O B$. We call this Case I. But, more likely, the unavailable DWH after disaster can't even operate for its own area. Thus, it might be necessary for the affected area to be assigned to a $B O B$. We call this situation Case II. 


\begin{tabular}{|l|l|r|r|r|r|r|r|r|}
\hline No. & Neighborhoods & \multicolumn{1}{|c|}{ Aiken } & Anderson & \multicolumn{1}{c|}{ Augusta } & \multicolumn{1}{c|}{ Beaufort } & \multicolumn{1}{c|}{ Camden } & \multicolumn{1}{c|}{ Clemson } & \multicolumn{1}{c|}{ Clinton } \\
\hline 1 & Aiken & 0.00 & 99.69 & 16.98 & 121.37 & 86.19 & 120.42 & 69.85 \\
\hline 2 & Anderson & 99.69 & 0.00 & 92.34 & 246.70 & 148.32 & 18.05 & 50.04 \\
\hline 3 & Augusta & 16.98 & 92.34 & 0.00 & 127.63 & 128.68 & 110.82 & 81.00 \\
\hline 4 & Beaufort & 121.37 & 246.70 & 127.63 & 0.00 & 166.79 & 271.49 & 181.15 \\
\hline 5 & Camden & 86.19 & 148.32 & 128.68 & 166.79 & 0.00 & 169.48 & 87.01 \\
\hline 6 & Clemson & 120.42 & 18.05 & 110.82 & 271.49 & 169.48 & 0.00 & 63.95 \\
\hline 7 & Clinton & 69.85 & 50.04 & 81.00 & 181.15 & 87.01 & 63.95 & 0.00 \\
\hline 8 & Conway & 186.02 & 253.07 & 228.30 & 188.83 & 110.14 & 264.79 & 190.71 \\
\hline 9 & Georgetown & 206.74 & 269.41 & 224.91 & 137.08 & 113.48 & 247.81 & 226.23 \\
\hline 10 & Greenwood & 55.53 & 39.50 & 62.00 & 167.60 & 102.90 & 56.53 & 26.97 \\
\hline 11 & Hilton Head & 152.40 & 277.66 & 158.59 & 41.02 & 198.23 & 239.42 & 196.77 \\
\hline 12 & Myrtle Beach & 207.12 & 266.99 & 225.29 & 202.69 & 124.06 & 262.91 & 204.74 \\
\hline 13 & Rock Hill & 124.47 & 120.98 & 142.64 & 206.76 & 71.32 & 120.00 & 65.57 \\
\hline 14 & Spartanburg & 142.14 & 60.36 & 160.32 & 225.30 & 125.80 & 59.19 & 35.54 \\
\hline 15 & Sumter & 112.39 & 172.26 & 130.57 & 125.70 & 29.34 & 168.17 & 104.57 \\
\hline 16 & Charleston & 162.96 & 226.73 & 207.56 & 70.32 & 146.74 & 248.36 & 170.50 \\
\hline 17 & Columbia & 56.41 & 116.50 & 75.10 & 134.16 & 34.69 & 128.22 & 61.20 \\
\hline 18 & Florence & 132.44 & 192.92 & 136.00 & 150.80 & 50.43 & 201.61 & 137.72 \\
\hline 19 & Greenville & 150.96 & 31.00 & 120.94 & 234.12 & 134.62 & 30.10 & 41.61 \\
\hline 20 & Orangeburg & 53.75 & 135.02 & 76.00 & 83.91 & 62.98 & 161.39 & 97.82 \\
\hline
\end{tabular}

Table 1(a). Distances (in miles) between Neighborhoods

\begin{tabular}{|c|c|c|c|c|c|c|c|c|}
\hline No. & Neighborhoods & Conway & Georgetown & Greenwood & Hilton Head & Myrtle Beach & Rock Hill & Spartanburg \\
\hline 1 & Aiken & 186.02 & 206.74 & 55.53 & 152.40 & 207.12 & 124.47 & 142.14 \\
\hline 2 & Anderson & 253.07 & 269.41 & 39.50 & 277.66 & 266.99 & 120.98 & 60.36 \\
\hline 3 & Augusta & 228.30 & 224.91 & 62.00 & 158.59 & 225.29 & 142.64 & 160.32 \\
\hline 4 & Beaufort & 188.83 & 137.08 & 167.60 & 41.02 & 202.69 & 206.76 & 225.30 \\
\hline 5 & Camden & 110.14 & 113.48 & 102.90 & 198.23 & 124.06 & 71.32 & 125.80 \\
\hline 6 & Clemson & 264.79 & 247.81 & 56.53 & 239.42 & 262.91 & 120.00 & 59.19 \\
\hline 7 & Clinton & 190.71 & 226.23 & 26.97 & 196.77 & 204.74 & 65.57 & 35.54 \\
\hline 8 & Conway & 0.00 & 36.62 & 218.67 & 193.54 & 14.03 & 186.15 & 223.24 \\
\hline 9 & Georgetown & 36.62 & 0.00 & 247.64 & 157.04 & 34.76 & 232.88 & 258.84 \\
\hline 10 & Greenwood & 218.67 & 247.64 & 0.00 & 183.21 & 232.70 & 89.97 & 59.39 \\
\hline 11 & Hilton Head & 193.54 & 157.04 & 183.21 & 0.00 & 191.40 & 210.80 & 231.61 \\
\hline 12 & Myrtle Beach & 14.03 & 34.76 & 232.70 & 191.40 & 0.00 & 200.16 & 237.25 \\
\hline 13 & Rock Hill & 186.15 & 232.88 & 89.97 & 210.80 & 200.16 & 0.00 & 61.93 \\
\hline 14 & Spartanburg & 223.24 & 258.84 & 59.39 & 231.61 & 237.25 & 61.93 & 0.00 \\
\hline 15 & Sumter & 80.81 & 79.19 & 116.18 & 138.17 & 94.56 & 87.32 & 130.47 \\
\hline 16 & Charleston & 97.41 & 60.92 & 191.91 & 104.98 & 97.34 & 186.88 & 205.42 \\
\hline 17 & Columbia & 140.20 & 123.04 & 72.81 & 142.64 & 146.75 & 67.33 & 93.13 \\
\hline 18 & Florence & 53.11 & 68.54 & 165.08 & 170.49 & 67.14 & 96.09 & 170.14 \\
\hline 19 & Greenville & 231.03 & 266.62 & 51.09 & 234.53 & 244.49 & 89.80 & 29.09 \\
\hline 20 & Orangeburg & 124.74 & 105.96 & 95.52 & 102.33 & 138.49 & 108.05 & 129.92 \\
\hline
\end{tabular}

Table 1(b). Distances (in miles) between Neighborhoods (continued) 


\begin{tabular}{|c|c|c|c|c|c|c|c|c|}
\hline No. & Neighborhoods & Sumter & Charleston & Columbia & Florence & Greenville & Orangeburg & Demand \\
\hline 1 & Aiken & 112.39 & 162.96 & 56.41 & 132.44 & 150.96 & 53.75 & 29 \\
\hline 2 & Anderson & 172.26 & 226.73 & 116.50 & 192.92 & 31.00 & 135.02 & 26 \\
\hline 3 & Augusta & 130.57 & 207.56 & 75.10 & 136.00 & 120.94 & 76.00 & 196 \\
\hline 4 & Beaufort & 125.70 & 70.32 & 134.16 & 150.80 & 234.12 & 83.91 & 13 \\
\hline 5 & Camden & 29.34 & 146.74 & 34.69 & 50.43 & 134.62 & 62.98 & 8 \\
\hline 6 & Clemson & 168.17 & 248.36 & 128.22 & 201.61 & 30.10 & 161.39 & 12 \\
\hline 7 & Clinton & 104.57 & 170.50 & 61.20 & 137.72 & 41.61 & 97.82 & 9 \\
\hline 8 & Conway & 80.81 & 97.41 & 140.20 & 53.11 & 231.03 & 124.74 & 12 \\
\hline 9 & Georgetown & 79.19 & 60.92 & 123.04 & 68.54 & 266.62 & 105.96 & 9 \\
\hline 10 & Greenwood & 116.18 & 191.91 & 72.81 & 165.08 & 51.09 & 95.52 & 23 \\
\hline 11 & Hilton Head & 138.17 & 104.98 & 142.64 & 170.49 & 234.53 & 102.33 & 48 \\
\hline 12 & Myrtle Beach & 94.56 & 97.34 & 146.75 & 67.14 & 244.49 & 138.49 & 32 \\
\hline 13 & Rock Hill & 87.32 & 186.88 & 67.33 & 96.09 & 89.80 & 108.05 & 72 \\
\hline 14 & Spartanburg & 130.47 & 205.42 & 93.13 & 170.14 & 29.09 & 129.92 & 37 \\
\hline 15 & Sumter & 0.00 & 106.14 & 43.41 & 39.28 & 150.20 & 56.99 & 41 \\
\hline 16 & Charleston & 106.14 & 0.00 & 114.54 & 109.92 & 214.24 & 75.98 & 121 \\
\hline 17 & Columbia & 43.41 & 114.54 & 0.00 & 79.49 & 100.91 & 40.83 & 130 \\
\hline 18 & Florence & 39.28 & 109.92 & 79.49 & 0.00 & 177.93 & 90.34 & 38 \\
\hline 19 & Greenville & 150.20 & 214.24 & 100.91 & 177.93 & 0.00 & 137.71 & 62 \\
\hline 20 & Orangeburg & 56.99 & 75.98 & 40.83 & 90.34 & 137.71 & 0.00 & 13 \\
\hline
\end{tabular}

Table 1(c). Distances (in miles) between Neighborhoods (continued) and Demands

To further investigate the effects of the shutdown of DWHs and to see the performance of the robust models, we consider various shutdown scenarios, present the resulting costs for both cases in Table 3, and compare the results for the three models.

As expected, the total transportation cost (TTC) for each model increases under the shutdown scenario and the increase in TTC are also reported in Tables 2(a), 2(b), 2 (c) and 3. For the IFL model, the TTC goes from $\$ 47,451.54$ to $69,995.04$, a $47.5 \%$ increase. We observe that, on average, two robust models, RIFL and RCFL, outperform than the non-robust IFL model under the shutdown scenario, though they underperform under the normal scenario.

Now, we propose a performance measure index, which is called a robustness index (RI) to show how much the results from each model are robust enough to cover the diverse scenarios in terms of cost minimization. Although there are many definitions of robustness, we adopt the one from Dong (2006) as "the extent to which the network is able to perform its function despite some damage done to it, such as the removal of some of the nodes and/or link in a network." In this paper, each model's performance may be evaluated by comparing it with the best performing model in terms of average TTC and its standard deviation. Hence we propose the following robustness index (RI):

RI for a model $g$ is defined as 


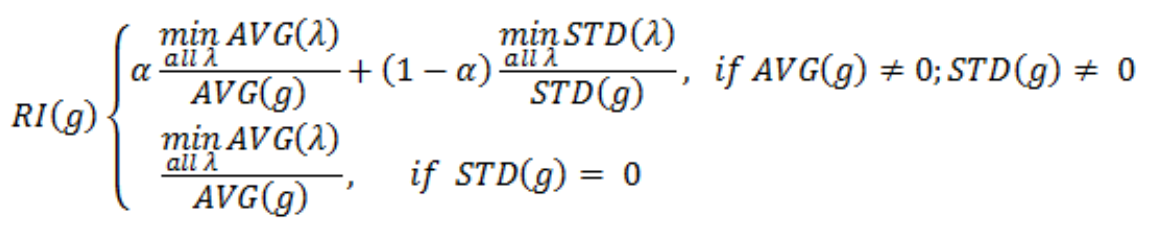

where $\operatorname{AVG}(\lambda)$ and $\operatorname{STD}(\lambda)$ stand for average and standard deviation of each model $\lambda$ 's cost under given scenarios and $a$ denotes the weight between the average and the standard deviation. Note that as RI for the model becomes closer to 1 , the more robust the model would be. And RI can be used to decide the rank of each model in terms of robustness. We calculate RI for the three models for all possible shutdown scenarios and present them in Table 3. We calculate three different RIsRI for a normal scenario and for Case I and Case II under the shutdown scenario, and an overall RI for both cases with the assumption that all individual scenarios have the same weight. As the RI values indicate, the IFL is most efficient under normal scenario, whereas the RIFL and RCFL seem to be the most robust for Case II and for Case I, respectively, under shutdown scenario. That is, on average, these robust models generate a slightly higher TTC for the normal scenario, but produce a lower TTC for the shutdown case than IFL.

\begin{tabular}{|c|c|c|}
\hline Model & \multicolumn{2}{|c|}{ IFL } \\
\hline Scenario & Normal & Shutdown \\
\hline $\begin{array}{l}\text { DWH } \\
\text { Selected }\end{array}$ & $\begin{array}{l}\text { 1. Charleston } \\
\text { 2. Columbia } \\
\text { 3. Greenville }\end{array}$ & $\begin{array}{l}\text { 1. Charleston } \\
\text { 3. Greenville }\end{array}$ \\
\hline $\begin{array}{l}\text { BOBs covered } \\
\text { by (DWH \#) }\end{array}$ & $\begin{array}{l}\text { 1. Beaufort (1) } \\
\text { 2. Aiken (2) } \\
\text { 3. Sumter(2) } \\
\text { 4. Anderson (3) } \\
\text { 5. Spartanburg (3) }\end{array}$ & $\begin{array}{l}\text { 1. Beaufort (1) } \\
\text { 2. Aiken (3) } \\
\text { 3. Sumter(1) } \\
\text { 4. Anderson (3) } \\
\text { 5. Spartanburg (3) }\end{array}$ \\
\hline $\begin{array}{l}\text { Neighborhoods } \\
\text { Assigned to } \\
\text { (BOB) }\end{array}$ & $\begin{array}{l}\text {-(Beaufort), Hilton- Head } \\
\text {-(Aiken), Augusta, Orangeburg } \\
\text {-(Sumter), Camden Conway, Florence, } \\
\text { Georgetown, Myrtle-Beach } \\
\text {-(Anderson), Clemson, Greenwood } \\
\text {-(Spartanburg) } \\
\text { Clinton, Rock Hill }\end{array}$ & $\begin{array}{l}\text {-(Beaufort), Hilton- Head } \\
\cdot \text { (Aiken), Orangeburg } \\
\text { •(Sumter), Camden Conway, } \\
\text { Florence, Georgetown, Myrtle- } \\
\text { Beach } \\
\text { •(Anderson),August Clemson, } \\
\text { Greenwood } \\
\text {-(Spartanburg) } \\
\text { Clinton, Rock Hill }\end{array}$ \\
\hline (CDB,CBN) TTC & $\begin{array}{c}(\$ 29116, \$ 18,335) \\
\$ 47,451 \\
(A)\end{array}$ & $\begin{array}{c}(\$ 36,889, \$ 33,105) \\
\$ 69,995 \\
(B)\end{array}$ \\
\hline $\begin{array}{l}\text { Increase } \\
\text { (B)-(A) }\end{array}$ & \multicolumn{2}{|c|}{$\$ 22,543$} \\
\hline
\end{tabular}

Table 2(a). Results comparison for normal/shutdown scenarios for three models 


\begin{tabular}{|c|c|c|}
\hline Model & \multicolumn{2}{|c|}{ RIFL } \\
\hline Scenario & Normal & Shutdown \\
\hline $\begin{array}{l}\text { DWH } \\
\text { Selected }\end{array}$ & $\begin{array}{l}\text { 1. Charleston } \\
\text { 2. Columbia } \\
\text { 3. Orangeburg }\end{array}$ & $\begin{array}{l}\text { 1. Charleston } \\
\text { 3. Orangeburg }\end{array}$ \\
\hline $\begin{array}{l}\text { BOBs covered } \\
\text { by (DWH \#) }\end{array}$ & $\begin{array}{l}\text { 1. Beaufort (1) } \\
\text { 2. Camden(2) } \\
\text { 3. Sumter (2) } \\
\text { 4. Clinton (2) } \\
\text { 5. Aiken (3) }\end{array}$ & $\begin{array}{l}\text { 1. Beaufort (1) } \\
\text { 2. Camden(3) } \\
\text { 3. Sumter (3) } \\
\text { 4. Clinton (3) } \\
\text { 5. Aiken (3) }\end{array}$ \\
\hline $\begin{array}{l}\text { Neighborhoods } \\
\text { Assigned to } \\
\text { (BOB) }\end{array}$ & $\begin{array}{l}\text {-(Beaufort), Hilton-Head } \\
\text {-(Camden), Rock Hill } \\
\text {-(Sumter), Conway, Florence, } \\
\text { Georgetown, Myrtle-Beach } \\
\text {-(Clinton),Anderson, Clemson, } \\
\text { Greenwood, Spartanburg, Greenville, } \\
\text {-(Aiken), Augusta }\end{array}$ & $\begin{array}{l}\text {-(Beaufort), Hilton- Head } \\
\text {-(Camden), Rock Hill } \\
\text {-(Sumter), Conway, Florence, } \\
\text { Georgetown, Myrtle-Beach } \\
\text {-(Clinton), Anderson, Clemson, } \\
\text { Spartanburg, Greenville, } \\
\text {-(Aiken), Augusta, Greenwood }\end{array}$ \\
\hline (CDB,CBN) TTC & $\begin{array}{c}(\$ 35,231, \$ 23,216) \\
\$ 58,448 \\
(A)\end{array}$ & $\begin{array}{c}(\$ 44,462, \$ 23,873) \\
\$ 68,335 \\
(B)\end{array}$ \\
\hline $\begin{array}{l}\text { Increase } \\
\text { (B)-(A) }\end{array}$ & \multicolumn{2}{|c|}{$\$ 9,887$} \\
\hline
\end{tabular}

Table 2(b). Results comparison for normal/shutdown scenarios for three models (continued)

\begin{tabular}{|c|c|c|}
\hline Model & \multicolumn{2}{|c|}{ RCFL } \\
\hline Scenario & Normal & Shutdown \\
\hline $\begin{array}{l}\text { DWH } \\
\text { Selected }\end{array}$ & $\begin{array}{l}\text { 1. Charleston } \\
\text { 2. Columbia } \\
\text { 3. Greenville }\end{array}$ & $\begin{array}{l}\text { 1. Charleston } \\
\text { 3. Greenville }\end{array}$ \\
\hline $\begin{array}{l}\text { BOBs covered } \\
\text { by (DWH \#) }\end{array}$ & $\begin{array}{l}\text { 1. Beaufort (1) } \\
\text { 2. Georgetown(1) } \\
\text { 3. Aiken (2) } \\
\text { 4. Anderson (3) } \\
\text { 5. Spartanburg (3) }\end{array}$ & $\begin{array}{l}\text { 1. Beaufort (1) } \\
\text { 2. Georgetown(1) } \\
\text { 3. Aiken (3) } \\
\text { 4. Anderson (3) } \\
\text { 5. Spartanburg (3) }\end{array}$ \\
\hline $\begin{array}{l}\text { Neighborhoods } \\
\text { Assigned to } \\
\text { (BOB) }\end{array}$ & $\begin{array}{l}\text {-(Beaufort), Hilton-Head } \\
\text {-(Georgetown), Conway, Myrtle-Beach, } \\
\text { Sumter, Florence } \\
\text {-(Aiken), Augusta, Camden, } \\
\text { Orangeburg } \\
\text {-(Anderson), Clemson, Greenwood } \\
\text {-( Spartanburg) } \\
\text { Clinton, Rock Hill }\end{array}$ & $\begin{array}{l}\text {-(Beaufort), Hilton-Head } \\
\text {-(Georgetown), Conway, Myrtle- } \\
\text { Beach, Sumter, Florence } \\
\text {-(Aiken), Orangeburg } \\
\text {-(Anderson), August, Clemson, } \\
\text { Greenwood } \\
\text {-( Spartanburg), Camden } \\
\text { Clinton, Rock Hill }\end{array}$ \\
\hline (CDB,CBN) TTC & $\begin{array}{c}(\$ 31,531, \$ 19,992) \\
\$ 51,523 \\
(A)\end{array}$ & $\begin{array}{c}(\$ 30,303, \$ 35,079) \\
\$ 65,383 \\
(B)\end{array}$ \\
\hline $\begin{array}{l}\text { Increase } \\
\text { (B)-(A) }\end{array}$ & \multicolumn{2}{|c|}{$\$ 13,860$} \\
\hline
\end{tabular}

Table 2(c). Results comparison for normal/shutdown scenarios for three models (continued) 


\begin{tabular}{|c|c|c|c|c|c|c|c|c|c|}
\hline \multirow{4}{*}{$\begin{array}{l}\text { Shutdown } \\
\text { Scenario }\end{array}$} & \multicolumn{9}{|c|}{ Model } \\
\hline & \multicolumn{3}{|c|}{ IFL } & \multicolumn{3}{|c|}{ RIFL } & \multicolumn{3}{|c|}{ RCFL } \\
\hline & \multirow{2}{*}{ Normal } & \multicolumn{2}{|c|}{ Shutdown } & \multirow{2}{*}{ Normal } & \multicolumn{2}{|c|}{ Shutdown } & \multirow{2}{*}{ Normal } & \multicolumn{2}{|c|}{ Shutdown } \\
\hline & & Case I & Case II & & Case I & Case II & & Case I & Case II \\
\hline DWH 1 & $\$ 47,451$ & $\$ 51,345$ & $\$ 70,000$ & $\$ 58,448$ & $\$ 59,277$ & $\$ 77,372$ & $\$ 47,451$ & $\$ 51,345$ & $\$ 70,000$ \\
\hline DWH 2 & $\$ 47,451$ & $\$ 69,995$ & $\$ 85,883$ & $\$ 58,448$ & $\$ 68,335$ & $\$ 81,033$ & $\$ 51,523$ & $\$ 65,383$ & $\$ 81,271$ \\
\hline DWH 3 & $\$ 47,451$ & $\$ 58,017$ & $\$ 65,573$ & $\$ 58,448$ & $\$ 59,046$ & $\$ 60,316$ & $\$ 47,500$ & $\$ 56,265$ & $\$ 63,834$ \\
\hline $\begin{array}{l}\text { DWHs } 1 \& \\
2\end{array}$ & $\$ 47,451$ & $\$ 85,958$ & $\$ 130,222$ & $\$ 58,448$ & $\$ 69,164$ & $\$ 100,523$ & $\$ 56,716$ & $\$ 80,770$ & $\$ 125,034$ \\
\hline DWHs 2 \& & $\$ 47,451$ & $\$ 107,307$ & $\$ 142,028$ & $\$ 58,448$ & $\$ 117,534$ & $\$ 139,085$ & $\$ 52,478$ & $\$ 101,848$ & $\$ 135,829$ \\
\hline $\begin{array}{l}\text { DWHs } 1 \& \\
3\end{array}$ & $\$ 47,451$ & $\$ 61,911$ & $\$ 88,849$ & $\$ 58,448$ & $\$ 62,940$ & $\$ 82,306$ & $\$ 48,550$ & $\$ 58,001$ & $\$ 84,141$ \\
\hline AVG & $\$ 47,451$ & $\$ 72,422$ & $\$ 97,093$ & $\$ 58,448$ & $\$ 72,716$ & $\$ 90,106$ & $\$ 50,703$ & $\$ 68,935$ & $\$ 93,252$ \\
\hline STD & 0 & $\$ 20,824$ & $\$ 31,742$ & 0 & $\$ 22,376$ & $\$ 27,203$ & $\$ 3,617$ & $\$ 19,107$ & $\$ 29,851$ \\
\hline RI & 1 & 0.934 & 0.892 & 0.811 & 0.900 & 1 & 0.468 & 1 & 0.938 \\
\hline $\begin{array}{l}\text { Overall } \\
\text { AVG }\end{array}$ & \multicolumn{3}{|c|}{$\$ 72,321$} & \multicolumn{3}{|c|}{$\$ 73,756$} & \multicolumn{3}{|c|}{$\$ 70,996$} \\
\hline $\begin{array}{l}\text { Overall } \\
\text { STD }\end{array}$ & \multicolumn{3}{|c|}{$\$ 29,305$} & \multicolumn{3}{|c|}{$\$ 23,289$} & \multicolumn{3}{|c|}{$\$ 26,392$} \\
\hline Overall RI & \multicolumn{3}{|c|}{0.888} & \multicolumn{3}{|c|}{0.981} & \multicolumn{3}{|c|}{0.941} \\
\hline $\begin{array}{l}\text { *AVG and S } \\
\text { *Alpha (a) is } \\
\text { DWH 1: Cha } \\
\text { DWH 2: Colu } \\
\text { DWH 3: Gre }\end{array}$ & $\begin{array}{l}\text { and for av } \\
00.5 \text { for } \\
n \text { for all } n \\
\text { for all } m \\
\text { for IFL }\end{array}$ & $\begin{array}{l}\text { e and sta } \\
\text { Is. } \\
\text { CFL, Ora }\end{array}$ & rd deviatic & & & & & & \\
\hline
\end{tabular}

Table 3. Comparison between integrated and two robust models

For Case I under the shutdown scenario, RIFL generates the highest TTC among the three models for the normal scenario and generates a slightly lower TTC than IFL. For the same weight between the average and the standard deviation, i.e., $\alpha=0.5$, the overall RI also indicates that RIFL has the highest robustness, followed by RCFL and IFL in this order. The threshold value for $a$, denoted by $\tilde{\alpha}$, turns out to be 0.7586 . It implies that for $\alpha \geq \tilde{\alpha}$, RCFL seems to be the most robust model, followed by RIFL and IFL.

From Table 3, we recommend that the proposed robust models, RIFL and RCFL, be used for optimally locating DWHs under the risk of disruptions. As discussed previously, transport of relief goods happens mostly after disaster. Therefore, for siting emergency response facilities, it would be more important to minimize the post-disaster cost rather than the pre-disaster cost and to better consider the unavailability of emergency facilities. The example provided here clearly demonstrates that the proposed robust facility location models can well suit the needs of siting emergency response facilities.

\section{Summary and conclusions}

In this paper, we develop an IFL (Integrated Facility Location) model and propose two robust models and compare them with a non-robust IFL. For the RCFL (Robust Continuous Facility Location) model, we introduce a continuous variable, defined in Equation (13), to denote the capacity constraint on a candidate $D W H$ in disasterprone areas, so that it can only partially satisfy the demand of BOBs. We formulate the problem as a mixed integer linear programming model and solve it using CPLEX for Microsoft Excel Add-In. For the RIFL (Robust Integer Facility Location) model, 
we set the constraint requiring each $B O B$ to be served by multiple $D W H$ s (two $D W H s$ in this paper) on the IFL model, which requires each $B O B$ to be served by one $D W H$. We propose a performance measure index to show how well the models perform after disaster, RI, defined in (19). Using numerical examples, we show that the two robust models, RIFL and RCFL, yield emergency response facility location plans of slightly higher TTCs (total transportation cost) than the IFL model under normal situations. However, they generate more robust facility location plans in the sense that they can perform better when some of the selected DWHs are shut down after disaster and these unavailable DWHs can't distribute emergency supplies to the affected areas (Case II).

The purpose of establishing emergency response facilities is for distributing relief goods after disaster. Therefore, when evaluating the efficiency and robustness of emergency response facility location plans, more weight should be given to their post-disaster performance. The resulting RIFL and RCFL models are designed in a robust manner such that they can better address scenarios with failures of key transportation infrastructure. Case studies are conducted to demonstrate the developed model's capability to deal with uncertainties in transportation networks. Thus, the developed robust models can help federal and local emergency response officials develop efficient and robust disaster relief plans.

For future research, it would be necessary to develop a robust model when both a $D W H$ and $a B O B$ could be unavailable in the shutdown scenario. In addition, we implicitly assume that each $D W H$ always carries enough inventories of emergency relief goods, so that for the shutdown scenario the other $D W H(\mathrm{~s})$ can ship enough relief goods to the extra $B O B s$. Thus, it would be also interesting to include the constraint on the capacity of DWHs in any proposed model.

\section{References}

Berman, O., Krass, D., \& Menezes, M.B.C. (2007). Facility reliability issues in network p-median problems: Strategic centralization and co-location effects. Operations Research, 55(2), 332-350. http://dx.doi.org/10.1287/opre.1060.0348

Cui, T.Y., Ouyang, Y., \& Shen, Z.J. (2010). Reliable facility locations design under the risk of disruptions. Operations Research, 58(4), 998-1011. http://dx.doi.org/10.1287/opre.1090.0801 
Daganzo, C. (2005). Logistics System Analysis, (4 ${ }^{\text {th }}$ Ed.). Berlin, Germany: Springer.

Dekle, J., Lavieri, M.S., Martin, E., Emir-Farinas, H., \& Francis, R. (2005). A Florida county locates disaster recovery centers. Interfaces, 35(2), 133-139. http://dx.doi.org/10.1287/inte.1050.0127

Dong, M. (2006). Development of supply chain network robustness index. International Journal of Services Operations and Informatics, 1(1/2), 54-66.

Eiselt, H.A., Gendreau, M., \& Laporte, G. (1996). Optimal location of facilities on a network with an unreliable node or link. Information Processing Letters, 58(2), 71-74. http://dx.doi.org/10.1016/0020-0190(96)00024-5

Hassin, R., Ravi, R., \& Salman, F.S. (2010). Facility location on a network with unreliable links, Working paper. Retrieved May 30, 2010, from http://www.di.unipi.it/di/groups/optimize/Events/proceedings/M/B/4/MB4-4.pdf.

Horner, M.W., \& Downs, J.A. (2007). Testing a flexible geographic information system-based network flow model for routing hurricane disaster relief goods. Transportation Research Record, 2022, 47-54. http://dx.doi.org/10.3141/2022-06

Langevin, A., Mbaraga, P., \& Campbell, J. (1996). Continuous approximation models in freight distribution: An Overview. Transportation Research Part B, 30 (3), 163-188. http://dx.doi.org/10.1016/0191-2615(95)00035-6

Li, X., \& Ouyang, Y. (2010). Effects of failure correlation on reliable facility location: A continuum approximation approach. Proceedings of the 89th Transportation Research Board 2010 Annual Meeting, in CD-ROM support. Washington DC.

Snyder, L.V., \& Daskin, M.S. (2005). Reliability models for facility location: The expected failure cost case, Transportation Science, 39(3), 400-416. http://dx.doi.org/10.1287/trsc. 1040.0107

Journal of Industrial Engineering and Management, 2012 (www.jiem.org)

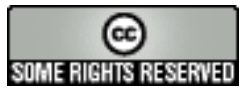

\footnotetext{
Article's contents are provided on a Attribution-Non Commercial 3.0 Creative commons license. Readers are allowed to copy, distribute and communicate article's contents, provided the author's and Journal of Industrial Engineering and Management's names are included. It must not be used for commercial purposes. To see the complete license contents, please visit http://creativecommons.org/licenses/by-nc/3.0/.
} 